OPEN ACCESS

Edited by:

Oscar Vilarroya,

Autonomous University of Barcelona,

Spain

Reviewed by:

Adolf Tobena,

Autonomous University of Barcelona,

Spain

Yoni Levy,

Interdisciplinary Center Herzliya, Israel

*Correspondence:

Agustín Ibáñez

aibanez@ineco.org.ar

${ }^{t}$ These authors have contributed equally to this work

Specialty section:

This article was submitted to Personality and Social Psychology, a section of the journal

Frontiers in Psychology

Received: 26 September 2018

Accepted: 10 January 2019

Published: 29 January 2019

Citation:

Baez S, Santamaría-García H and Ibáñez A (2019) Disarming Ex-Combatants' Minds: Toward Situated Reintegration Process in

Post-conflict Colombia.

Front. Psychol. 10:73.

doi: 10.3389/fpsyg.2019.00073

\section{Disarming Ex-Combatants' Minds: Toward Situated Reintegration Process in Post-conflict Colombia}

\author{
Sandra Baez ${ }^{1 \dagger}$, Hernando Santamaria-García ${ }^{2,3+}$ and Agustín Ibáñez $4,5,6,7,8 *$ \\ ${ }^{1}$ Departamento de Psicología, Universidad de los Andes, Bogotá, Colombia, ${ }^{2}$ Centro de Memoria y Cognición, \\ Intellectus-Hospital Universitario San Ignacio, Bogotá, Colombia, ${ }^{3}$ Physiology and Psychiatry, Pontificia Universidad \\ Javeriana, Bogotá, Colombia, ${ }^{4}$ Laboratory of Experimental Psychology and Neuroscience, Institute of Cognitive \\ and Translational Neuroscience, INECO Foundation, Favaloro University, Buenos Aires, Argentina, ${ }^{5}$ National Scientific \\ and Technical Research Council, Buenos Aires, Argentina, ${ }^{6}$ Center for Social and Cognitive Neuroscience, School \\ of Psychology, Universidad Adolfo Ibáñez, Santiago, Chile, ${ }^{7}$ Universidad Autónoma del Caribe, Barranquilla, Colombia, \\ ${ }^{8}$ ARC Centre of Excellence in Cognition and its Disorders, Sydney, NSW, Australia
}

Collective violence in the context of armed conflict impacts the economy, health systems, and social stability of affected countries. This is considered a complex phenomenon with interwoven biological, psychological, social, cultural, and political factors. However, most of the research on this topic still lacks suitable established integrative approaches to assess multilevel perspectives. Social, cognitive and affective mental processes (SCAMP) are critical factors that should be considered in multilevel approaches. In this article, we critically discuss some of the classically isolated approaches used in violence research, the absence of successful interventions for excombatants reintegration, and the specific neglect of SCAMP in these interventions. We present the case of post-conflict Colombia as a unique opportunity to study the different roots of collective violence, and we call for a more robust and situated approach to understanding of and intervention in this multifaceted phenomenon. In addition, we suggest a two-stage approach for addressing ex-combatants' reintegration programs, which considers the situated nature of post-conflict scenarios and the urgent need for evidence-based interventions. This approach focuses on the comprehensive scientific assessment of specific factors involved in violence exposure and the subsequent design of successful interventions. The implementation of this approach will contribute to the effective reintegration of individuals who have been exposed to extreme violence for more than 50 years.

Keywords: collective violence, armed conflict, reintegration process, post-conflict Colombia, ex-combatants

\section{POST-CONFLICT COLOMBIA: TAKING THE LABORATORY INTO THE FIELD}

Collective violence within the context of armed conflicts is a scourge with great impacts on human society. Numerous civil wars and armed conflicts across the globe (e.g., Congo, Syria, Israel-Palestine, Colombia) exemplify the pervasive and ubiquitous nature of human violence (Muchembled, 2010). Collective violence in armed conflicts impacts the economy, health systems, and social stability of affected countries. Consequently, numerous efforts have been made to try to understand the determinants and consequences of this phenomenon. In this line, important 
research questions have been addressed by different approaches from the social sciences (Mike, 2018), biology (Raine, 2013) and, more recently, neuroscience (Poldrack et al., 2018). However, most of this research still lacks properly integrated and established approaches to assess multilevel (social, cultural, political, biological, and neurocognitive) perspectives. In this article, we question some of the classically isolated approaches that have been used for violence in armed conflicts research, the lack of evidence-based interventions that have been employed in the reintegration of ex-combatant's or veterans, and the neglect of social, cognitive and affective mental processes (SCAMP) that has been seen in these interventions. We present the case of postconflict Colombia as a unique scenario for studying the different roots of collective violence, and we call for a more robust, systematic and established approach for the understanding of and intervention in this multifaceted phenomenon. We suggest a two-stage approach (research on specific factors and subsequent development of evidence-based interventions) for addressing reintegration programs, which considers the established nature of post-conflict scenarios and the urgent need of evidence-based interventions.

The Colombian conflict is a great example of the inherent complexity of the sources, actors and effects of violence. Across more than 50 years of army conflict, Colombia has nearly 363,374 victims of violence. This includes 363,374 victims of threats, 22,915 victims of sexual offenses, 167,809 victims of enforced disappearance, 7,265,072 victims of forced displacement and 11,140 victims of anti-personnel mines (Amnesty International Report 2017/18, 2018). Different societal factors impact the Colombian armed conflict, including territorial conflicts, socioeconomic inequities, forced displacement and even cultural factors that normalize violent behaviors (Bohorquez et al., 2009; Reardon, 2018). Violence in Colombia has been exerted by drug cartels, Marxist-Leninist guerrillas (e.g., FARC and ELN), paramilitary armies, and national army forces, among other actors.

The government and the Revolutionary Armed Forces of Colombia (FARC) reached a peace agreement in 2016 to end their 52-year armed conflict. In 2017, the United Nations mission in Colombia verified that the FARC had handed over its weapons and demobilized. However, a minority of dissident guerrilla fighters rejected the terms of the peace agreement, have not disarmed, and continue to commit violent acts. Currently, civilians continue to face death threats and violence from National Liberation Army (ELN) guerrillas and paramilitary successor groups that emerged after a demobilization process that occurred a decade ago (Human Rights Watch World Report, 2018). Thus, post-conflict Colombia has represented a source of other types of violence rather than a peaceful scenario. This new sociopolitical climate has allowed for a renewed interest in exploring the origins, consequences, predictors, and resilience factors of violence, as well as the social-cognitive and psychological effects in ex-combatants, victims and civil populations (LeGrand et al., 2017; Flores and Vargas, 2018; Reardon, 2018). Moreover, it favors opportunities for developing integrative research and opens the door for designing new evidence-based and personalized interventions to propel social reintegration processes.

\section{THE LACK OF CURRENT REINTEGRATION INTERVENTIONS IN THE COLOMBIAN SCENARIO}

\section{The Neglect of Mental Health and SCAMP in the Ex-Combatants' Reintegration}

Ex-combatants usually display abnormal and exacerbated expressions of aggression and violent behavior (Betancourt et al., 2010; Hermenau et al., 2013; Kobach et al., 2015), which can persist even years after demobilization (Betancourt et al., 2010; Weierstall et al., 2012) (see Table 1 for a review of the available evidence). At the same time, combatants are exposed to numerous forms of extreme violence; they often witness, experience and perpetrate acts such as killing, torture, and rape. Exposure to violence, including organized violence, enhances the risk of mental disorders such as trauma-related illnesses, depression or substance abuse (Ikin et al., 2007; Odenwald et al., 2007a,b; Toomey et al., 2007; Ginzburg and Solomon, 2011; Maguen et al., 2011).

Despite this evidence, disarming and reintegrating the mind of ex-combatants is not currently considered a critical component of reintegration. Mental health and SCAMP have not been considered to be core topics for Colombian disarmament, demobilization, and reintegration (DDR) programs. Indeed, the effects of violence- and conflict-exposure on the mental health of ex-combatants have not been investigated in a rigorous and comprehensive manner. In addition, social cognition abilities have been proposed as important variables in relation to violent profiles (Bennette et al., 2005; Harenski et al., 2010; Jusyte and Schonenberg, 2017). In particular, social cognition skills allow individuals to encode information, interpret and predict the consequences of a particular action, and determine an appropriate response. It has been suggested (Bennette et al., 2005) that certain ways of processing social information help to protect the individual from personal, social, environmental, or situational pressures toward violent behavior. In addition, some studies have shown that, compared to non-violent offenders, violent offenders are significantly poorer on facialaffect recognition (Hoaken et al., 2007) and exhibit a deficit in the categorization of fearful expressions (Jusyte and Schonenberg, 2017). This deficit is associated with self-reported aggression and psychopathy levels (Jusyte and Schonenberg, 2017). In addition, criminal psychopaths show abnormal processing of moral scenarios (Harenski et al., 2010). They showed a negative association between moral violation severity ratings and posterior temporal activity that was not present in non-psychopaths.

\section{Evidence on Neuroscience of Group Conflicts}

Previous evidence has revealed a relationship between emotions and attitudes involved in intergroup conflicts. For instance, 


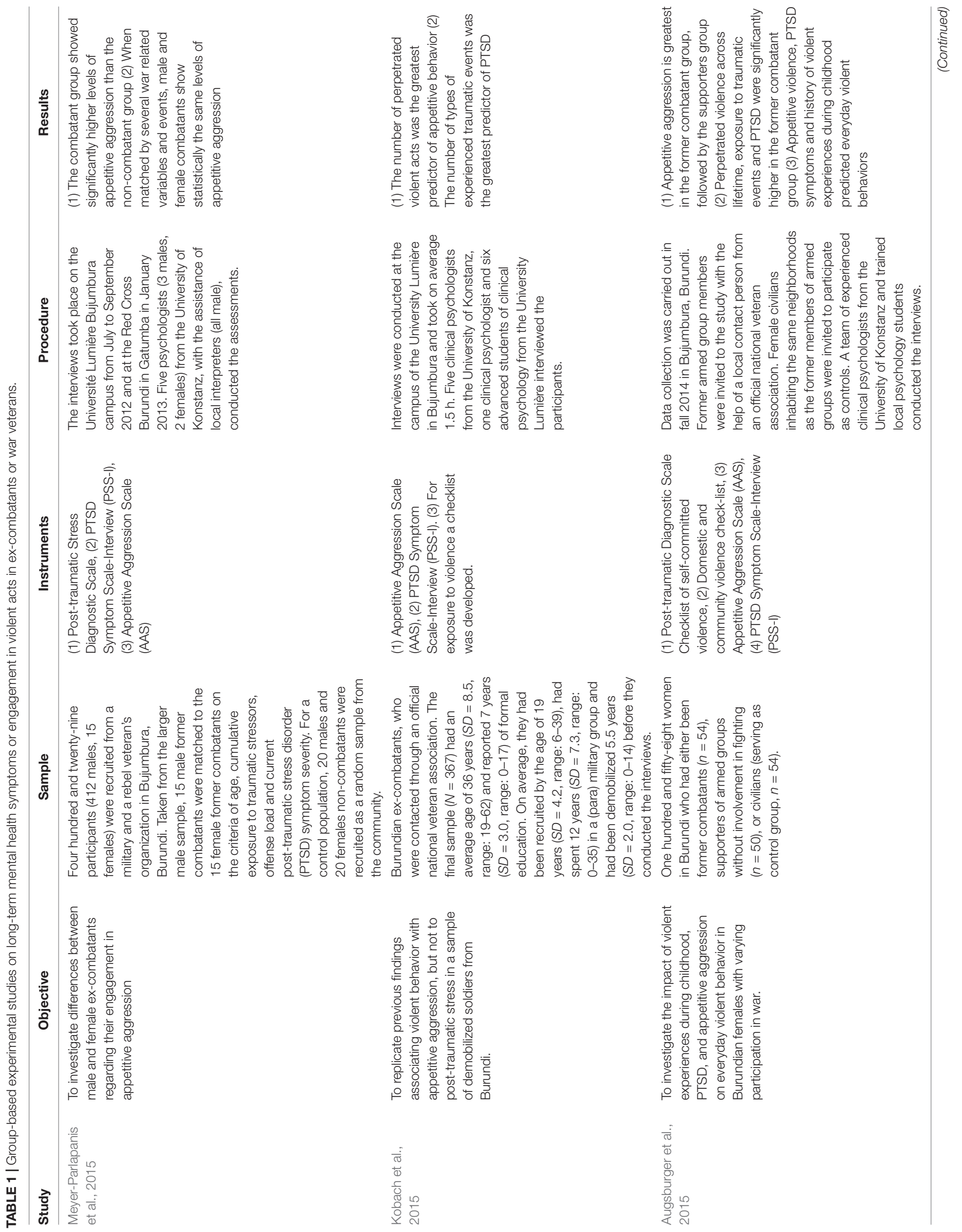




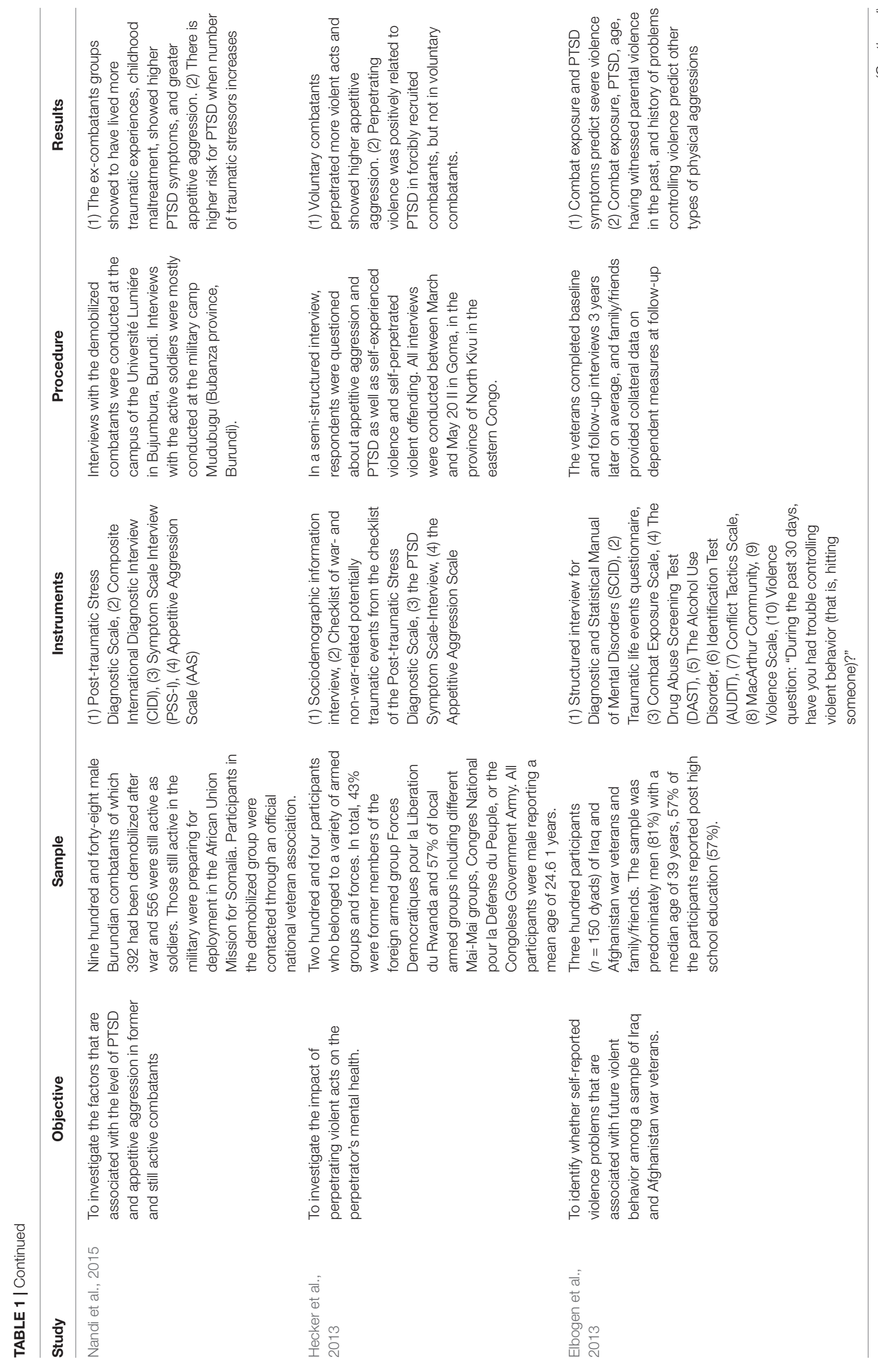




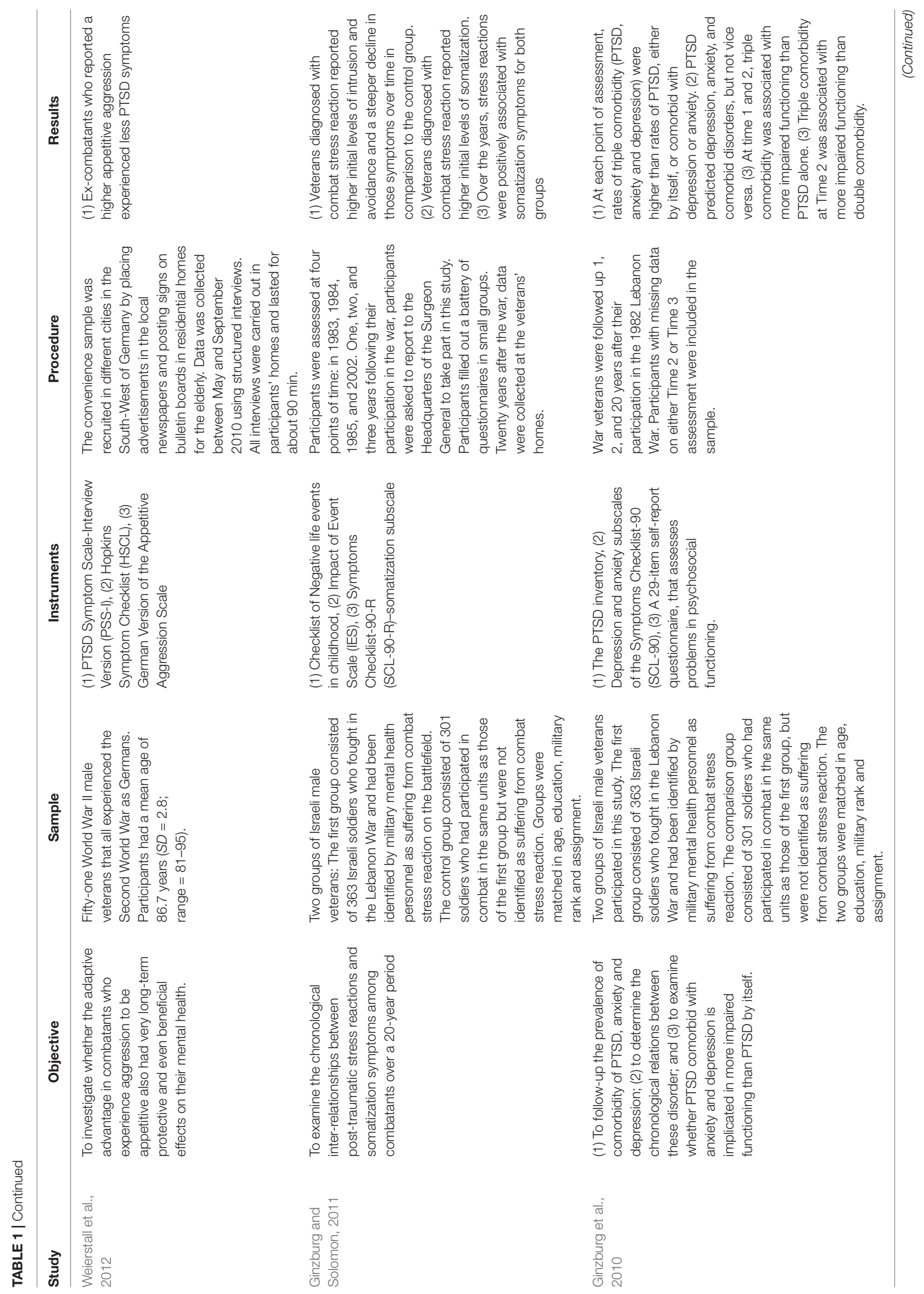




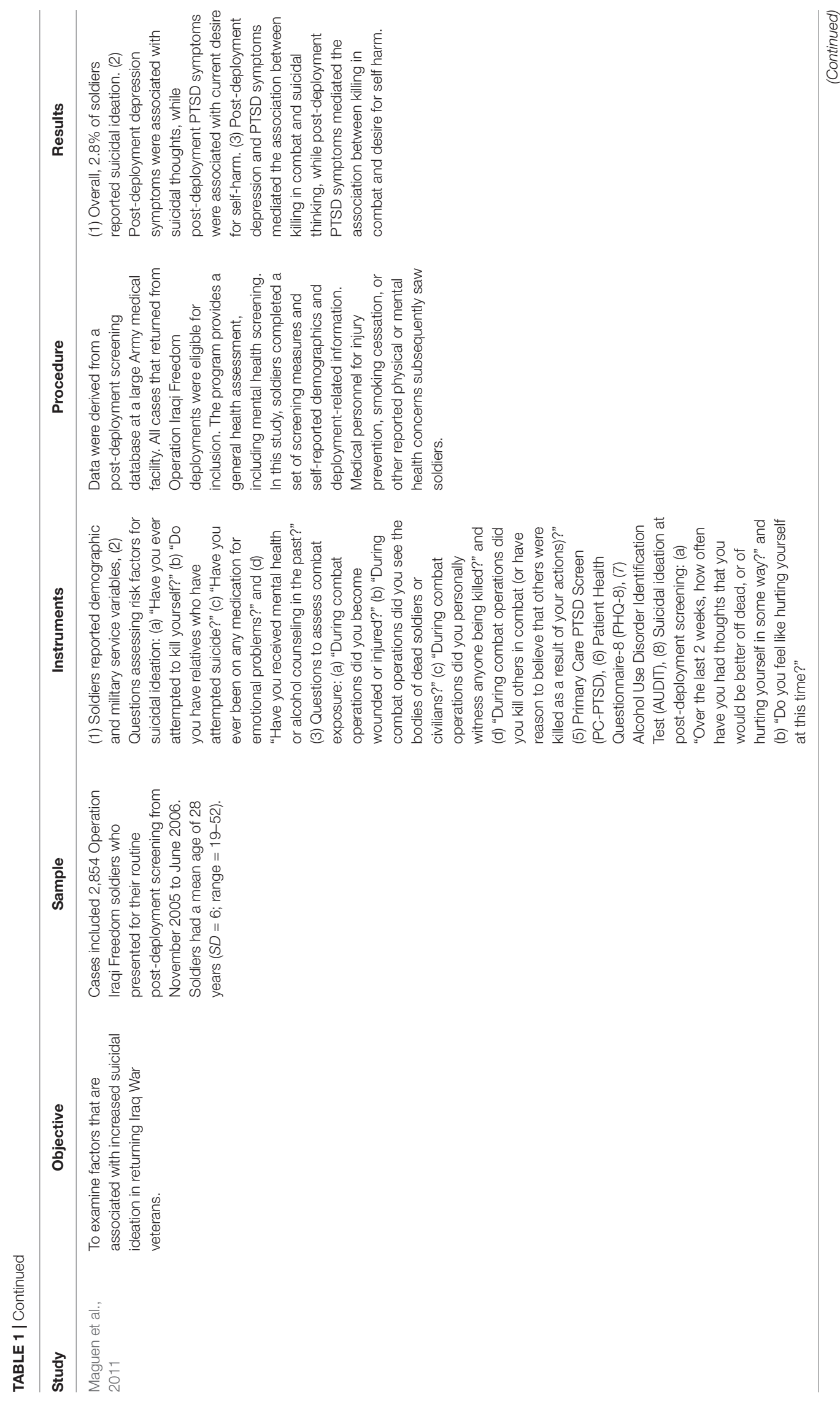




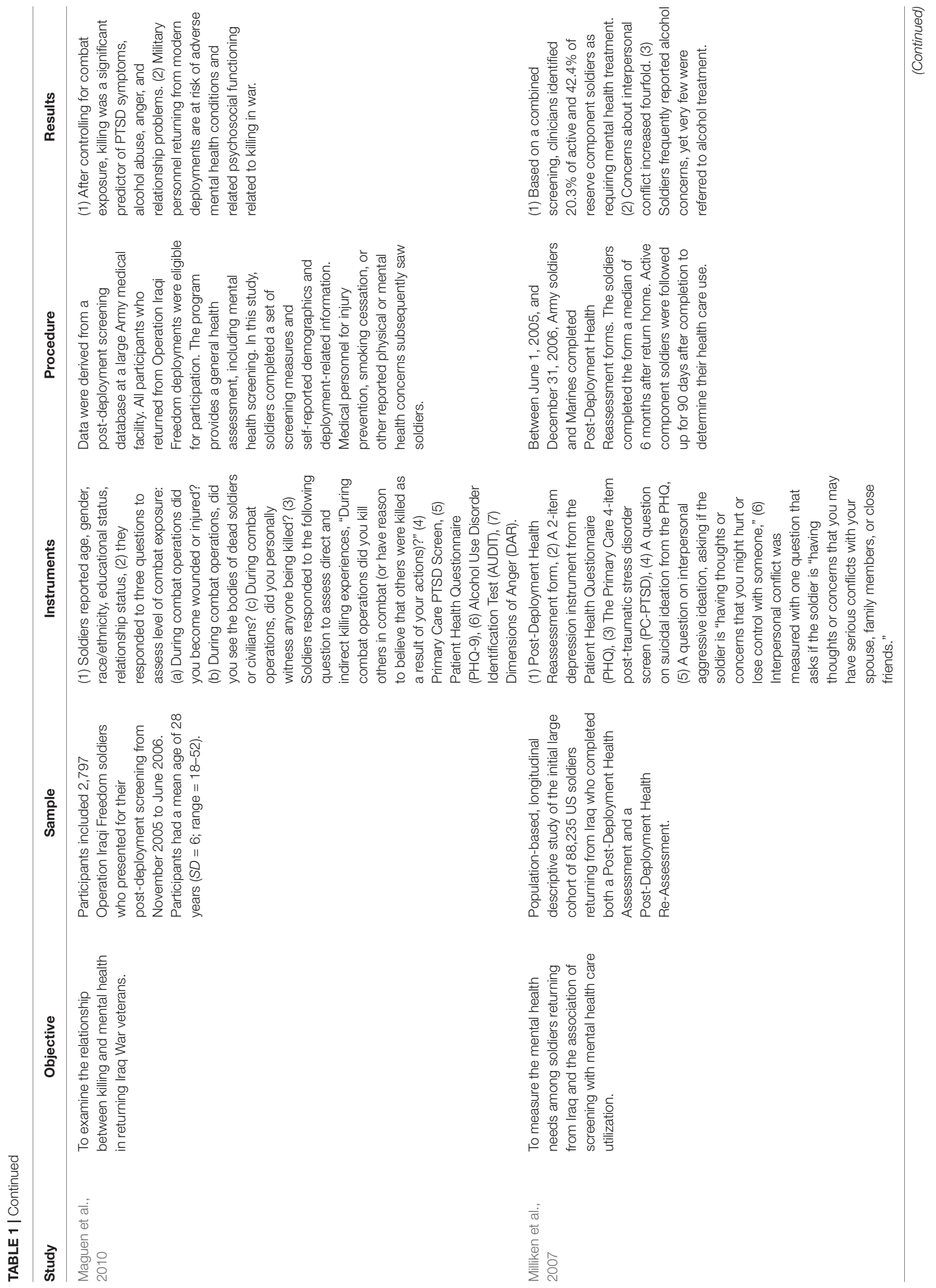




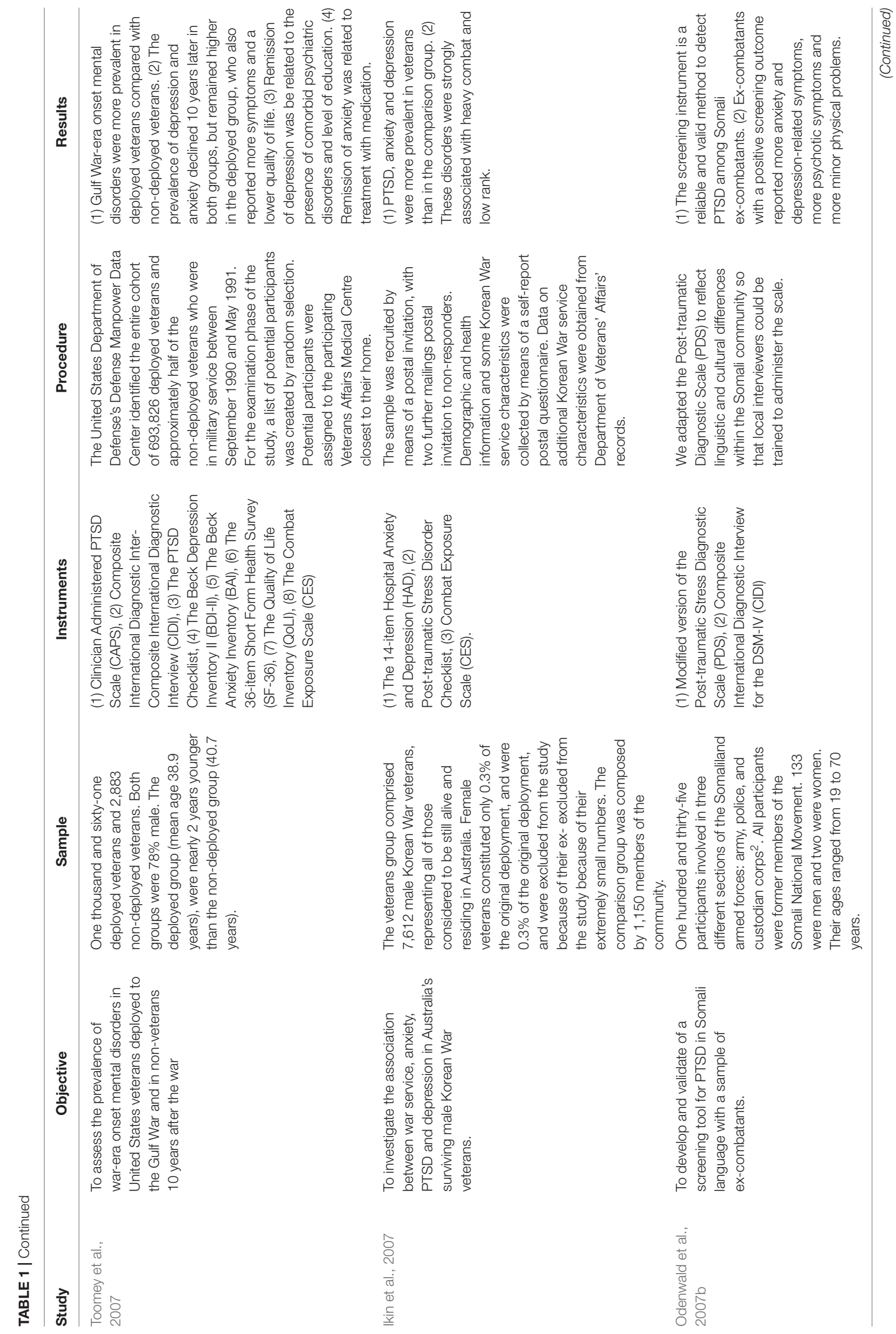




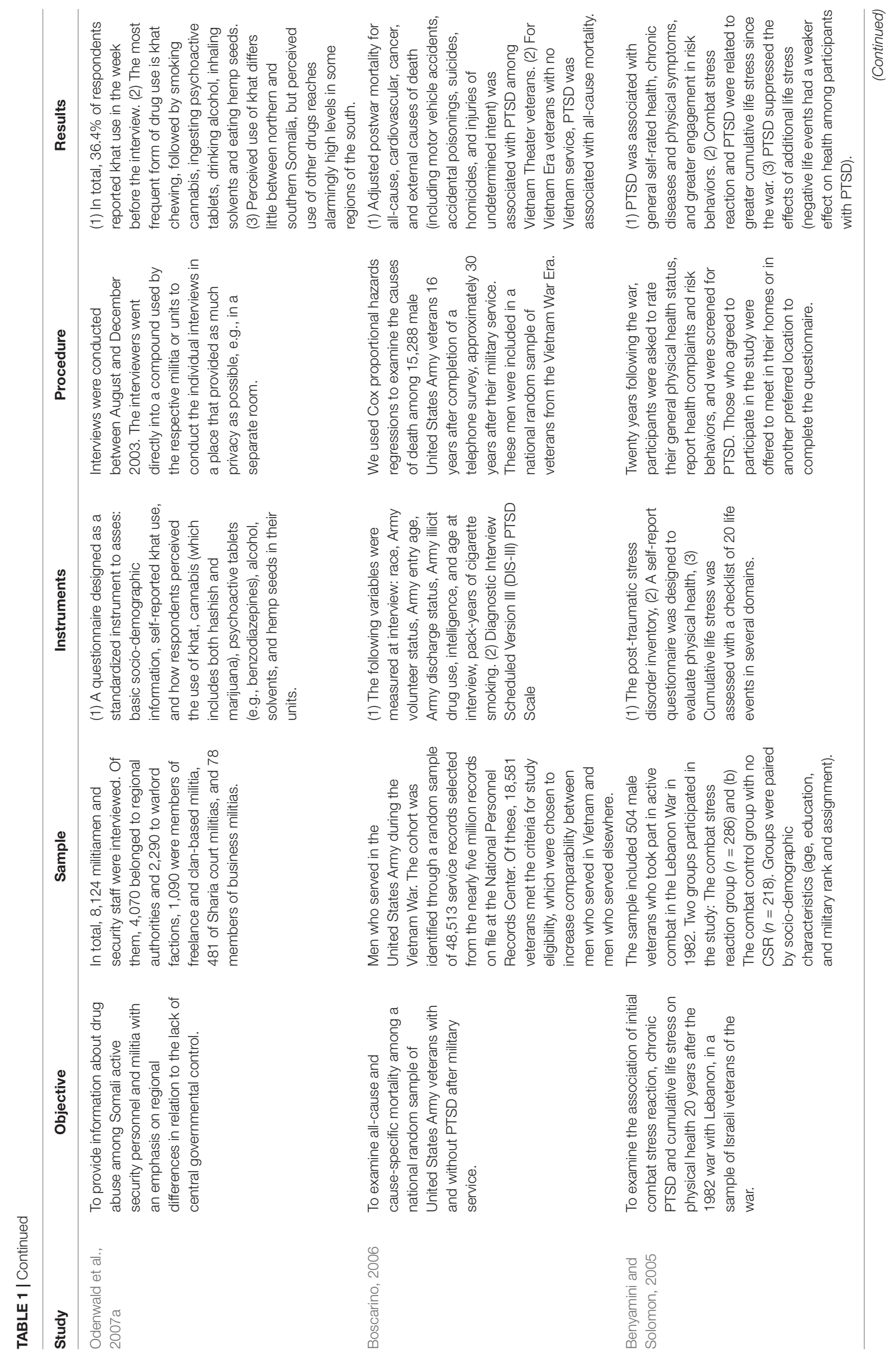




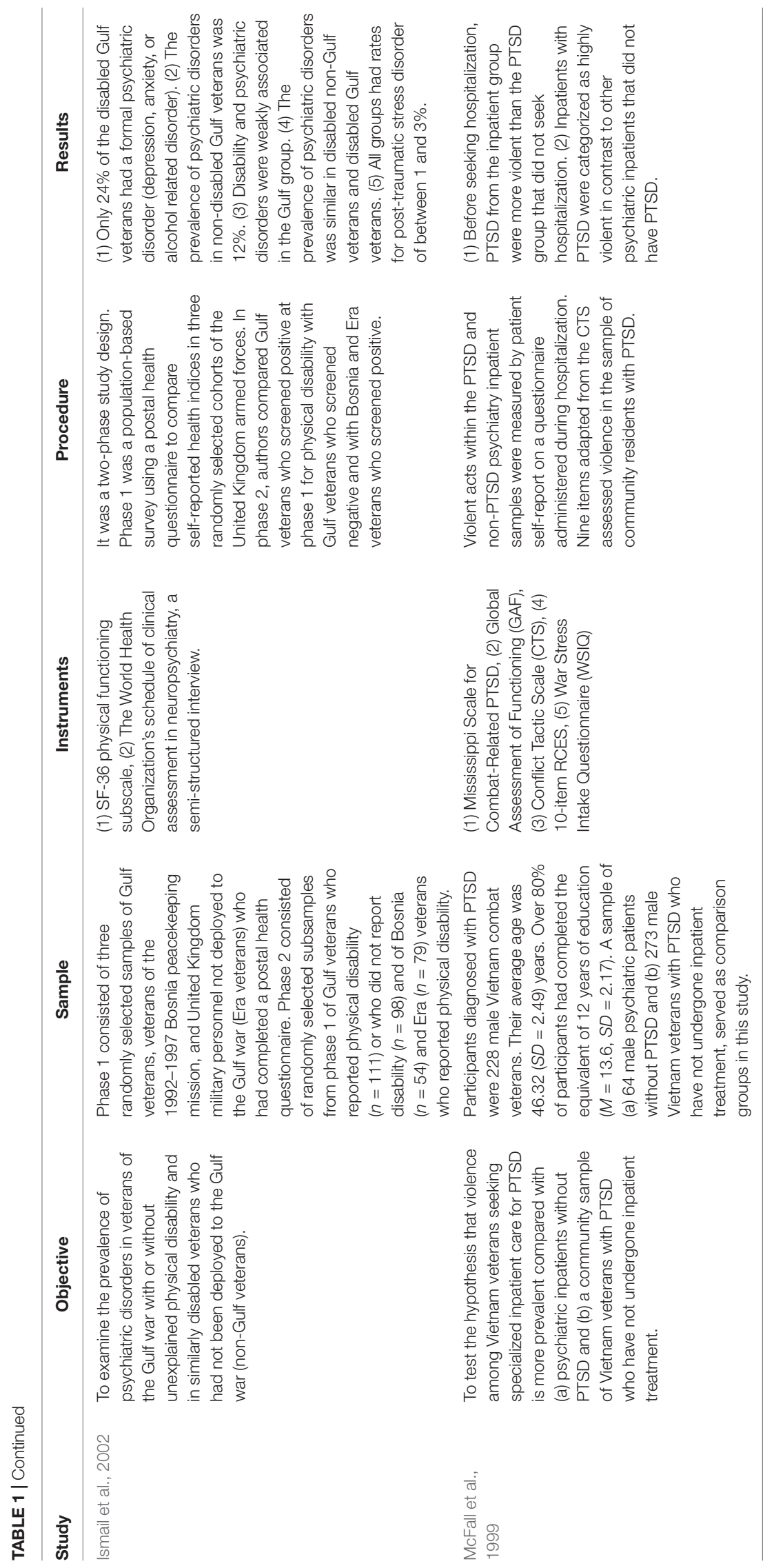


interpersonal-disgust sensitivity predicts negative attitudes toward immigrants, foreigners, and socially deviant groups (Hodson and Costello, 2007). This effect is mediated by ideological orientations (social dominance orientation, rightwing authoritarianism) and dehumanizing perceptions of the out-group. Moreover, anger influences automatic evaluations of out-groups because of its functional relevance to intergroup conflict and competition (DeSteno et al., 2004). Other negative emotions less relevant to intergroup relations (e.g., sadness) result in non-automatic intergroup bias (DeSteno et al., 2004).

In this line, cognitive neuroscience has investigated the neural basis of prejudice and stereotyping in an effort to identify the processes through which these biases influence behavior. Neuroimaging studies have shown that the amygdala is associated with race-related processing (Lieberman et al., 2005) and that the amount of amygdala activity correlates with racerelated prejudice (Cunningham et al., 2004). In this context, participants with greater implicit racial bias showed greater recruitment of brain regions supporting cognitive conflict and control (dorsal anterior cingulate cortex, dorsolateral prefrontal cortex, ventrolateral prefrontal cortex) (Richeson et al., 2003). This implicit racial bias modulates brain activity at very early time windows (Ibanez et al., 2009, 2010). These findings have allowed elucidating basic mechanisms of the social brain while advancing the understanding of intergroup bias in social behavior.

Additional evidence on neuroscience of group conflicts has approached to the understanding of neural markers of violent attitudes or behaviors. For instance, it has been found that youngsters who grow up in a climate of long-standing intergroup conflict inhibit the brain's automatic response to the pain of out-group members (Levy et al., 2016). Tighter brain-to-brain synchrony among group members in the ArabPalestinian minority enhanced the neural in-group bias (Levy et al., 2016). In the same line, a fMRI study in Arab, Israeli and control individuals showed that attitudes toward the outgroup are predicted by activity in the precuneus. Other brain regions that were involved in reasoning about emotionally laden information did not show this pattern (Bruneau and Saxe, 2010). Besides, it has been suggested (Molenberghs et al., 2016) that people show greater moral sensitivity for in-group versus out-group victims, but only when the perpetrator is from the out-group. This effect correlates with greater activity in the orbitofrontal cortex for in-group victims when outgroup individuals harmed them. It has been also reported that outcomes of social group competition can directly affect primary reward-processing neural systems (Cikara et al., 2011), which has implications for inter-group harm. Specifically, the ventral striatum activity, associated with subjective pleasure, also correlated with self-reported likelihood of aggressiveness against out-group members.

Together, available evidence suggests that social cognition abilities are relevant variables related to violent behaviors. Antecedents also highlight the importance of understanding how social factors shape violent behavior and the specific neural markers associated with violence in intergroup conflicts, and also emphasize the need to characterize the social cognition abilities of ex-combatants. Additionally, the findings of these studies underline the importance of including the stimulation/rehabilitation of social cognition processes in reintegration programs, as this is a crucial step to enhance the ability of ex-combatants to positively interact with social challenges in post-conflict scenarios.

\section{Limitations of Current Interventions}

To date, the effects of long-term exposure to violence and its impact on mental health are poorly understood. Some studies suggest an increased risk of developing post-traumatic stress disorder, depression or substance abuse (e.g., Ikin et al., 2007; Odenwald et al., 2007a,b; Toomey et al., 2007; Ginzburg and Solomon, 2011; Maguen et al., 2011, see Table 1 for a review of the available evidence); however, other aspects of mental health, such as the presence of axis 1 and 2 psychiatric symptoms/disorders and SCAMP, have not been systematically assessed in ex-combatants. Additionally, two major limitations of current research approaches is the use of problematic instruments for assessing mental health, such as self-report measures, and the small samples sizes. The neglect of SCAMP can directly impact the degree to which reintegration is successful after conflict. Thus, the characterization of the psychopathologic, psychiatric, and social-cognitive profiles of ex-combatants is crucial for the comprehensive implementation and evaluation of such programs.

Efforts to demobilize and disarm armed factions and to reintegrate ex-combatants into civilian life are critical for peace building processes (Humphreys and Weinstein, 2007), as these factors are essential in preventing the recurrence of conflict. However, in Colombia, most DDR interventions have been designed with consideration of political, security, occupational and socioeconomic dimensions, while neglecting mental health or social-cognitive disorders of ex-combatants. Despite the remarkable importance of such programs, most of the available interventions have crucial limitations that have not been addressed, including: (a) reduced scientific assessment of ex-combatants' mental health and SCAMP (as well as the concomitant scarcity of interventions focused on this aspect), (b) absent evidence regarding contextual and individual factors that explain whether individuals can successfully reintegrate after conflict, and (c) lack of rigorous assessment of intervention effectiveness and long-term effect.

Through the comprehensive characterization of the mental profiles of ex-combatants, it would be possible to design better interventions for the successful social reintegration of these individuals with potential long-terms effects. Only a few studies have attempted to provide evidence for the effectiveness of mental health interventions in ex-combatants (e.g., Hermenau et al., 2013; Trujillo et al., 2017, see Table 2 for a review of available evidence). Overall, these studies showed that specific interventions can reduce posttraumatic stress symptoms and aggressive attitudes and can enhance emotion recognition abilities. However, data on the long-term effects and the generalizability of these interventions are lacking. 


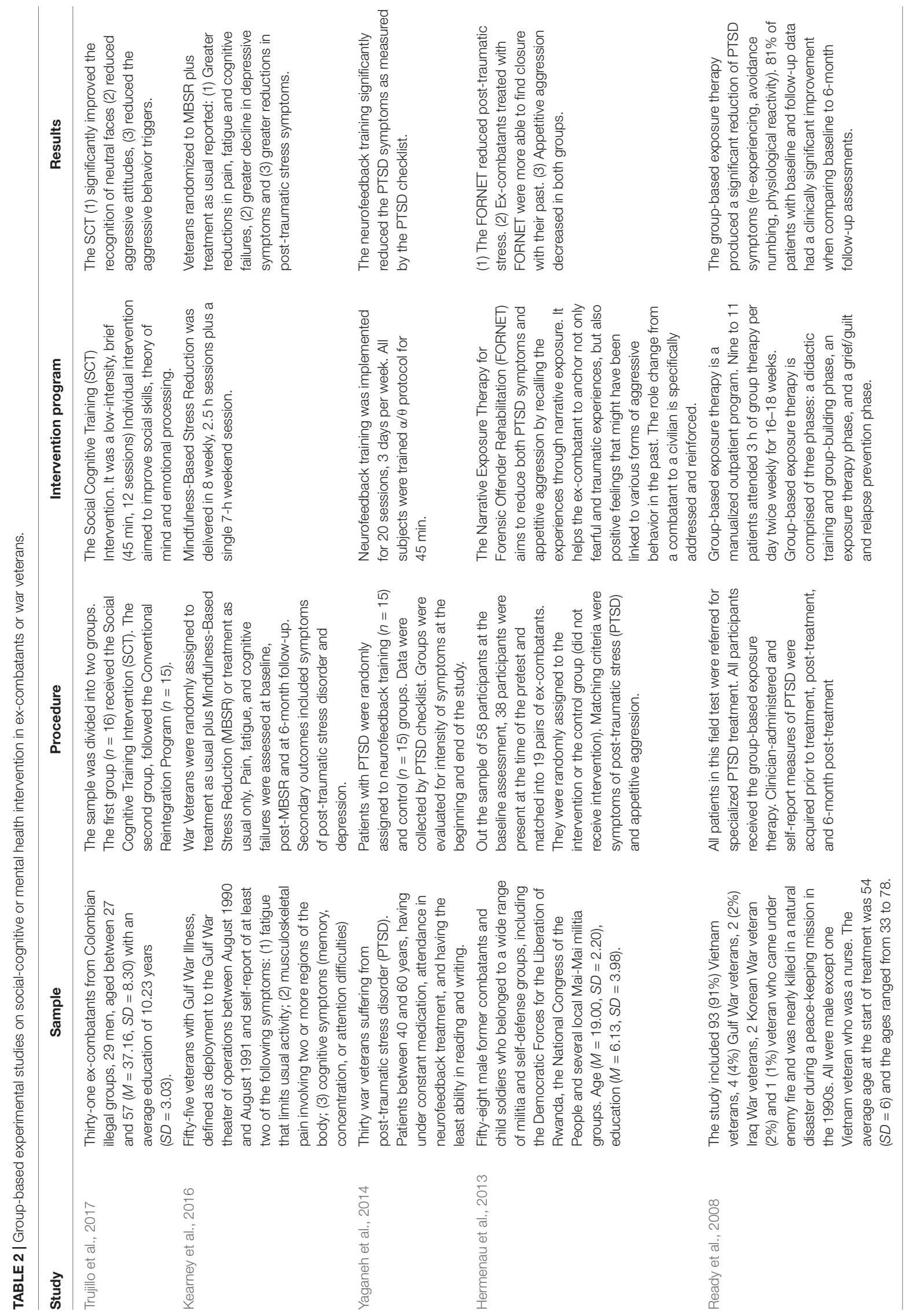




\section{TOWARD A TWO-STAGE APPROACH FOR REINTEGRATION INTERVENTIONS}

\section{First Stage: Understanding the Complexity of Collective Violence in Colombian Conflict}

Although there is a large body of literature on different aspects of violence that spans across centuries, new approaches that propel more integrated views combining social, cultural, political, biological and neuroscientific perspectives are still lacking. Moreover, general theoretical models of collective violence in armed conflicts should be supported with an established, regional approach that considers the intrinsic local factors involved in the conflict. The first stage of the proposed approach involves the development of an established model that considers the contextual conditions in which violence has emerged and assesses the interaction between interpersonal and intrapersonal factors that could promote violent behaviors. Thus, before designing reintegration programs, it is crucial to understand the specific interplay between biological, psychological, social, political, and cultural factors involved in specific violent behaviors.

Violent behaviors to be studied by this approach should include different domains, according to the reasons to be involved in direct violence. These include: (a) consequentialist violence: violence committed by utilitarian reasons following the principle of the end justify means (Baez et al., 2017); (b) appetitive violence: primary pleasure or enjoyment in executing illegal violent acts (Elbert et al., 2018); (c) retaliatory violence: violent acts as a result of revenge or retaliation (Chester and DeWall, 2016; Thrasher and Handfield, 2018); and (d) impulsive violence: aggressive or violent acts as a consequence of impulsive, uncontrolled anger episodes, associated to poor behavioral control mechanisms (Elbert et al., 2018).

Interdisciplinary efforts are urgently needed to build novel strategies for violence research that incorporate inclusive approaches regarding violence origins, individual differences in SCAMP and mental health, and other factors that perpetuate violence and their consequences. Similarly, it is crucial to assess the background, including the cultural, social, and political context where reintegration interventions will be implemented. Specifically, new research approaches should consider the assessment of both contextual (social, cultural, and political) and individual or person-centered (e.g., mental disorders symptoms, personality traits, cognitive and social cognitive skills, physical health, quality of life aspects) factors that could be associated with different domains of violence. For instance, contextual factors include the presence of threatening social experiences (e.g., stigmatization, discrimination or exclusion, antecedents of intrafamilial abuse, the accessing to social, educational and occupational resources, the presence of political situations that impel social conflict (e.g., censured expressions of political ideas and neglected group participation, the level of membership identification with the armed group, the presence of beliefs and attitudes that normalize and idealize the actions of armed groups and the presence of beliefs and attitudes toward the compliance for juridical regulations.) Contextual assessment should include experiences and factors present at different stages of subjects' life: before the subjects entered to the armed group, during the time they were part of the armed group, and after they leaved the armed group and accepted the reintegration processes.

The assessment of person-centered factors should include mental disorders symptoms, personality traits, basic cognitive abilities, social cognition skills and quality of life aspects. The last one involves the environment adaptation skills, social and emotional skills (skills to regulate emotional responses, resources to integrate social groups, presence of intimate relationships), determinants of psychical integrity and health (resources to satisfy basic health needs, presence of symptoms of physical alterations); and the self-projection skills.

Research approaches including a comprehensive assessment of both contextual and person-centered factors associated with different violence dimensions in ex-combatants, would contribute to the understanding of the specific interplay multidimensional factors involved in specific violent behaviors. Additionally, personalized assessments should identify both protective and risk factors for successful reintegration. Finally, more studies that anticipate the factors that may challenge successful reintegration and social participation processes are of critical relevance. This information is crucial for designing specific interventions within reintegration programs.

\section{Second Stage: Designing and Assessing Reintegration Interventions}

The second stage involves the design of evidence-based interventions grounded in the knowledge accumulated during the first stage. Given the scarcity of interventions designed specifically for ex-combatants, successful interventions employed in other populations may be considered examples for future designs.

For instance, some research in healthy non-offender populations (Leiberg et al., 2011; Klimecki et al., 2013) has shown that short-term mental training using meditation-based techniques increases prosocial behavior and positive affect toward people who were not specifically targeted during training. Contemplative mental training increases perceived social connectedness, reduces the detrimental effects of loneliness (Kok and Singer, 2017) and improves interoceptive accuracy and emotional awareness (Bornemann and Singer, 2017). In addition, mental training interventions for different cognitive and social skills can induce specific changes in brain morphology (Valk et al., 2017). These brain changes are correlated with training-induced behavioral improvements in domain-specific measures of attention, compassion, and perspective-taking. Similarly, evidence-based social interventions exist for patients with psychiatric disorders such as autism or schizophrenia (Kandalaft et al., 2013; Lindenmayer et al., 2013; Roberts et al., 2014). These interventions also have been shown to be useful in increasing social-cognitive abilities and social functioning. Preliminary studies (Mullins, 2010) have also been adapted into rehabilitation programs. Though originally designed for ordinary offenders, these approaches are being considered for the disengagement and deradicalization of Islamist terrorists. 
These types of interventions are focused on generating behavioral and belief changes. To date, there is no evidence for the longterm effectiveness of these interventions, and they have not been rigorously employed in ex-combatants from armed groups. Thus, empirical support for their effectiveness is urgently needed, as they have potential applications that may be useful in ex-combatants.

New technologies and advances in data analysis should also be considered for designing interventions. For instance, recent research has revealed the utility of machine learning and datamining methods to develop statistical models that aim to predict the risk for reoffense in violent criminals. These methods have the capacity to empirically discover patterns in the data and to construct suitably complex decision boundaries by using conventional predictors and a large sample size (Berk and Bleich, 2013). In this regard, recent studies have shown that risk assessments based on machine learning forecasts can improve parole release decisions (Berk, 2017) and might be able to provide timely and useful risk assessments for domestic violence (Berk et al., 2016). Additionally, these methods have been successfully used in forensic psychiatry to evaluate the risk for reoffense in mentally disordered individuals (Pflueger et al., 2015). In excombatants, machine-learning methods have been applied to regress specific traumatic events on appetitive aggression levels and post-traumatic stress profiles (Kobach et al., 2014). This study showed that the number of perpetrated violent acts was the best predictor of appetitive aggression, while traumatic events experienced was the best predictor of post-traumatic stress. Considering the available evidence from ordinary offenders and ex-combatants, machine learning and data-mining methods may be useful to evaluate the risk for reoffense, as well as to identify specific mental health profiles in ex-combatants and to design more personalized interventions.

In addition, insights from neuroscience could contribute to the understanding and (potentially) the prediction of violence and other forms of antisocial behavior present in ex-combatants. Cognitive neuroscience may contribute to the understanding of the neural basis of basic cognitive and social functions associated to violent behaviors. Besides, basic neuroscience could provide insights on aspects of brain function, structure, chemistry, or connectivity related to violence dimensions (Poldrack et al., 2018). In addition, some studies (Blair, 2013; Viding et al., 2014) have suggested the potential utility of neuroscience's methods for predicting future violent behavior. Other promising results (Doehrmann et al., 2013; GoldsteinPiekarski et al., 2016) suggest that neuroimaging measures can be incorporated as modeling tools to assess the predictive validity of treatment outcomes. The utility of neuroscience's methods for predicting future violent behavior offers the potential to identify critical neurocognitive mechanisms that distinguish between individuals who might benefit from treatment or preventive measures.

Specifically, our approach proposes the designing of longterm (at least 9 months) interventions that integrates individual, group and community strategies, matching aims with individual needs. Regarding individual interventions, it is worth to highlight that personalized interventions considering the individualized prescription of specific therapeutics (Schork, 2015) have been proposed as medical treatments. A similar approach could be considered in designing reintegration and rehabilitation interventions for ex-combatants. Individual differences in experience, ranging from intergenerational violence, sociopathy, psychopathy, and psychopathological (and even cognitive) profiles, are distributed across ex-combatant populations. Taking individual variability into account is essential for achieving successful reintegration into civilian life. In addition, these interventions should consider the context in which exposure to violence occurred and the socioeconomic and cultural characteristics of the geographic zone where reintegration will take place.

For instance, the proposed approach includes the adaptation of successful mental training interventions (Leiberg et al., 2011; Klimecki et al., 2013; Bornemann and Singer, 2017; Valk et al., 2017) for different cognitive and social skills, according to the ex-combatant's needs. These interventions may be implemented in small-group sessions and should consider different social cognition domains (i.e., emotion processing, theory of mind, empathy, and moral reasoning). For instance, following previous protocols implemented in healthy non-offender participants (Valk et al., 2017), group interventions may include various daily mental exercises and weekly instructed sessions. Specifically, training protocols would comprise meditation-based techniques and dyadic interpersonal exercises (Valk et al., 2017). At the beginning of each of training module, participants would be part of a retreat (intensive training phase). There, they would be introduced to the core exercises and ideas of the module and would learn to integrate the exercises into their daily routine. When accessible, an online platform and ongoing monitoring would support the participants in their daily practice at home. In addition, they would assist to a weekly group session guided by experienced teachers.

Group interventions should be complemented with individual sessions considering the ex-combatants personal needs. These individual interventions may be based in previous protocols implemented in ex-combatants populations (e.g., Hermenau et al., 2013; Trujillo et al., 2017). However, new protocols should be designed grounded in the knowledge accumulated during the first stage of the proposed approach. The adherence to individual and group sessions should be closely controlled.

Given that only a few studies (Hermenau et al., 2013; Trujillo et al., 2017) have attempted to provide evidence for the effectiveness of mental health and SCAMP interventions in ex-combatants, there is urgently needed to develop a rigorous assessment of interventions effectiveness and long-term effects. Our approach proposes different measures as indicators of reintegration interventions effectiveness, these include: (a) preand post-intervention assessment of basic and social cognition skills, (b) pre-and post-intervention assessment of mental health symptoms, (c) pre-and post-intervention assessment of violent/aggressive behaviors and attitudes, (d) pre-and postintervention assessment of socio-economic and occupational opportunities, and (e) self-reported acceptance of the excombatants by their communities and families. The use of ongoing monitoring of the intervention with principles of 
behavioral insights would help to promote engagement and reduce attrition.

Finally, the preparation of the receiving communities which are willing and able to accept ex-combatants is of particular importance to the success of social reintegration (Bowd and Özerdem, 2013). Reintegration processes require intervention on a societal-level. Disengagement from violence requires intervention at all levels and with all actors of the conflict, including deactivating the implicit normalization of violence within the culture. Community interventions aimed at reducing stigma and revengeful actions should be framed in new spaces of collective disarmament. Community sensitization exercises can be influential in preparing a community for reintegration and should be promoted. Education and support at this stage is vital to the development and fostering of trust between communities and ex-combatants (Bowd and Özerdem, 2013). Furthermore, the promotion of personal and collective emotional healing is needed to support the emergence of symbolic expressions as initiatives for building a national historical memory. Some successful local interventions in Colombia, such as the Mampuján weavers (Belalcazar Valencia, 2017), should be extended to other sectors of the country. These ongoing collective reintegration initiatives combine intrapersonal and collective factors toward reparation.

Post-conflict Colombia represents a unique opportunity to study the different roots of violence. The implementation of the proposed approach would contribute to the understanding of the multidimensional factors involved in violence and the efficiency of these interventions to change violent behaviors. The situated perspective supported by a comprehensive scientific assessment and the designing of evidence-based interventions constitute the major strengthens of this proposal. However, some limitations and challenges should also be acknowledged. First, the implementation of the two-stage approach critically demand long-term funding from governmental and non-governmental agencies. Second, this proposal demands a concerted effort from academics, social science and mental health professionals, as

\section{REFERENCES}

Amnesty International Report 2017/18 (2018). Amnesty Int. Avaliable at: https://www.amnesty.org/es/countries/americas/colombia/report-colombia/

Augsburger, M., Meyer-Parlapanis, D., Bambonye, M., Elbert, T., and Crombach, A. (2015). Appetitive aggression and adverse childhood experiences shape violent behavior in females formerly associated with combat. Front. Psychol. 6:1756. doi: 10.3389/fpsyg.2015.01756

Baez, S., Herrera, E., Garcia, A., Manes, F., Young, L., and Ibanez, A. (2017). Outcome-oriented moral evaluation in terrorists. Nat. Hum. Behav. 1:118. doi: 10.1038/s41562-41017-40118

Belalcazar Valencia, J. G. (2017). The weavings of mampuján women: aestheticartistic practices of situated memory in the colombian armed conflict context. Andamios 14, 59-85.

Bennette, S., Farrington, D., and Huesmann, L. (2005). Explaining gender differences in crime and violence: the importance of social cognitive skills. Aggress. Violent Behav. 10, 263-288. doi: 10.1016/j.avb.2004. 07.001

Benyamini, Y., and Solomon, Z. (2005). Combat stress reactions, posttraumatic stress disorder, cumulative life stress, and physical health among Israeli veterans twenty years after exposure to combat. Soc. Sci. Med. 61, 1267-1277. doi: 10. 1016/j.socscimed.2005.01.023 well as communities and governments. Third, as any longterm intervention, high rates of drop out or withdrawal may be present. To circumvent this issue, the adherence of excombatants to interventions should be closely controlled.

\section{CONCLUDING REMARKS}

The proposed two-stage approach involves long-term interventions that critically demand funding from governmental and non-governmental agencies. The implementation of an established evidence-based intervention in post-conflict Colombia demands a concerted effort from academics, social science and mental health professionals, and communities and governments, accompanied by economic and social support. Long-term, evidence-based and established interventions would contribute to the successful reintegration and rehabilitation of individuals and communities that have been exposed to extreme violence for more than 50 years.

\section{AUTHOR CONTRIBUTIONS}

SB and HS-G wrote the first draft. All authors designed the proposal, searched the literature, participated in discussing the contents of the paper, contributed to editing and approved the final version of the manuscript.

\section{FUNDING}

This work was partially supported by grants from CONICET, CONICYT/FONDECYT Regular (1170010), FONCyT-PICT 2017-1818, FONCyT-PICT 2017-1820, FONDAP 15150012, the INECO Foundation, and Global Brain Health Institute (GBHIUCSF).

Berk, R. (2017). An impact assessment of machine learning risk forecasts on parole board decisions and recidivism. J. Exp. Criminol. 13, 193-216. doi: 10.1007/ s11292-017-9286-2

Berk, R., and Bleich, J. (2013). Statistical procedures for forecasting criminal behavior. Criminol. Public Policy 12, 513-544. doi: 10.1111/1745-9133. 12047

Berk, R., Sorenson, S. B., and Barnes, G. (2016). Forecasting domestic violence: a machine learning approach to help inform arraignment decisions. J. Empir. Legal Stud. 13, 94-115. doi: 10.1111/jels.12098

Betancourt, T. S., Borisova, I. I., Williams, T. P., Brennan, R. T., Whitfield, T. H., de la Soudiere, M., and Gilman, S. E. (2010). Sierra Leone's former child soldiers: a follow-up study of psychosocial adjustment and community reintegration. Child Dev. 81, 1077-1095. doi: 10.1111/j.1467-8624.2010.01455.x

Blair, R. J. (2013). The neurobiology of psychopathic traits in youths. Nat. Rev. Neurosci. 14, 786-799. doi: 10.1038/nrn3577

Bohorquez, J. C., Gourley, S., Dixon, A. R., Spagat, M., and Johnson, N. F. (2009). Common ecology quantifies human insurgency. Nature 462:911. doi: 10.1038/ nature08631

Bornemann, B., and Singer, T. (2017). Taking time to feel our body: steady increases in heartbeat perception accuracy and decreases in alexithymia over 9 months of contemplative mental training. Psychophysiology 54, 469-482. doi: 10.1111/ psyp. 12790 
Boscarino, J. A. (2006). Posttraumatic stress disorder and mortality among U.S. Army veterans 30 years after military service. Ann. Epidemiol. 16, 248-256. doi: 10.1016/j.annepidem.2005.03.009

Bowd, R., and Özerdem, A. (2013). How to assess social reintegration of excombatants. J. Interven. Statebuild. 7, 453-475. doi: 10.1080/17502977.2012. 727537

Bruneau, E. G., and Saxe, R. (2010). Attitudes towards the outgroup are predicted by activity in the precuneus in Arabs and Israelis. Neuroimage 52, 1704-1711. doi: 10.1016/j.neuroimage.2010.05.057

Chester, D. S., and DeWall, C. N. (2016). The pleasure of revenge: retaliatory aggression arises from a neural imbalance toward reward. Soc. Cogn. Affect. Neurosci. 11, 1173-1182. doi: 10.1093/scan/nsv082

Cikara, M., Botvinick, M. M., and Fiske, S. T. (2011). Us versus them: social identity shapes neural responses to intergroup competition and harm. Psychol. Sci. 22, 306-313. doi: 10.1177/0956797610397667

Cunningham, W. A., Johnson, M. K., Raye, C. L., Chris Gatenby, J., Gore, J. C., and Banaji, M. R. (2004). Separable neural components in the processing of black and white faces. Psychol. Sci. 15, 806-813. doi: 10.1111/j.0956-7976.2004. 00760.x

DeSteno, D., Dasgupta, N., Bartlett, M. Y., and Cajdric, A. (2004). Prejudice from thin air: the effect of emotion on automatic intergroup attitudes. Psychol. Sci. 15, 319-324. doi: 10.1111/j.0956-7976.2004.00676.x

Doehrmann, O., Ghosh, S. S., Polli, F. E., Reynolds, G. O., Horn, F., Keshavan, A., et al. (2013). Predicting treatment response in social anxiety disorder from functional magnetic resonance imaging. JAMA Psychiatry 70, 87-97. doi: 10. 1001/2013.jamapsychiatry. 5

Elbert, T., Schauer, M., and Moran, J. K. (2018). Two pedals drive the bi-cycle of violence: reactive and appetitive aggression. Curr. Opin. Psychol. 19, 135-138. doi: 10.1016/j.copsyc.2017.03.016

Elbogen, E. B., Johnson, S. C., Newton, V. M., Fuller, S., Wagner, H. R., and Beckham, J. C. (2013). Self-report and longitudinal predictors of violence in Iraq and Afghanistan war era veterans. J. Nerv Ment. Dis. 201, 872-876. doi: 10.1097/NMD.0b013e3182a6e76b

Flores, T. E., and Vargas, J. F. (2018). Colombia: democracy, violence, and the peacebuilding challenge. 35, 581-586. doi: 10.1177_0738894218787786

Ginzburg, K., Ein-Dor, T., and Solomon, Z. (2010). Comorbidity of posttraumatic stress disorder, anxiety and depression: a 20-year longitudinal study of war veterans. J. Affect. Disord. 123, 249-257. doi: 10.1016/j.jad.2009.08.006

Ginzburg, K., and Solomon, Z. (2011). Trajectories of stress reactions and somatization symptoms among war veterans: a 20-year longitudinal study. Psychol. Med. 41, 353-362. doi: 10.1017/S0033291710000528

Goldstein-Piekarski, A. N., Korgaonkar, M. S., Green, E., Suppes, T., Schatzberg, A. F., Hastie, T., et al. (2016). Human amygdala engagement moderated by early life stress exposure is a biobehavioral target for predicting recovery on antidepressants. Proc. Natl. Acad. Sci. U.S.A. 113, 11955-11960. doi: 10.1073/ pnas. 1606671113

Harenski, C. L., Harenski, K. A., Shane, M. S., and Kiehl, K. A. (2010). Aberrant neural processing of moral violations in criminal psychopaths. J. Abnorm. Psychol. 119, 863-874. doi: 10.1037/a0020979

Hecker, T., Hermenau, K., Maedl, A., Hinkel, H., Schauer, M., and Elbert, T. (2013). Does perpetrating violence damage mental health? Differences between forcibly recruited and voluntary combatants in DR congo. J. Traumat. Stress 26, 142-148. doi: 10.1002/jts.21770

Hermenau, K., Hecker, T., Schaal, S., Maedl, A., and Elbert, T. (2013). Addressing post-traumatic stress and aggression by means of narrative exposure: a randomized controlled trial with ex-combatants in the eastern DRC. J. Aggress. Maltreatment Trauma 22, 916-934. doi: 10.1080/10926771.2013.824057

Hoaken, P. N., Allaby, D. B., and Earle, J. (2007). Executive cognitive functioning and the recognition of facial expressions of emotion in incarcerated violent offenders, non-violent offenders, and controls. Aggress. Behav. 33, 412-421. doi: 10.1002/ab.20194

Hodson, G., and Costello, K. (2007). Interpersonal disgust, ideological orientations, and dehumanization as predictors of intergroup attitudes. Psychol. Sci. 18, 691-698. doi: 10.1111/j.1467-9280.2007.01962.x

Human Rights Watch World Report (2018). Human. Rights Watch. Available at: https://www.hrw.org/es/world-report/2018

Humphreys, M., and Weinstein, J. (2007). Demobilization and reintegration. J. Conflict Resolut. 51, 531-567. doi: 10.1177/0022002707302790
Ibanez, A., Gleichgerrcht, E., Hurtado, E., Gonzalez, R., Haye, A., and Manes, F. F. (2010). Early neural markers of implicit attitudes: N170 modulated by intergroup and evaluative contexts in IAT. Front. Hum. Neurosci. 4:188. doi: 10.3389/fnhum.2010.00188

Ibanez, A., Haye, A., Gonzalez, R., Hurtado, E., and Henriquez, R. (2009). Multi-level analysis of cultural phenomena: the role of ERPs approach to prejudice. J. Theory Soc. Behav. 39, 89-110. doi: 10.1111/j.1468-5914.2008. 00391.x

Ikin, J. F., Sim, M. R., McKenzie, D. P., Horsley, K. W., Wilson, E. J., Moore, M. R., et al. (2007). Anxiety, post-traumatic stress disorder and depression in Korean War veterans 50 years after the war. Br. J. Psychiatry 190, 475-483. doi: 10.1192/bjp.bp.106.025684

Ismail, K., Kent, K., Brugha, T., Hotopf, M., Hull, L., Seed, P., et al. (2002). The mental health of UK Gulf war veterans: phase 2 of a two phase cohort study. BMJ 325:576. doi: 10.1136/bmj.325.7364.576

Jusyte, A., and Schonenberg, M. (2017). Impaired social cognition in violent offenders: perceptual deficit or cognitive bias? Eur. Arch. Psychiatry Clin. Neurosci. 267, 257-266. doi: 10.1007/s00406-016-0727-0

Kandalaft, M. R., Didehbani, N., Krawczyk, D. C., Allen, T. T., and Chapman, S. B. (2013). Virtual reality social cognition training for young adults with highfunctioning autism. J. Autism Dev. Disord. 43, 34-44. doi: 10.1007/s10803-0121544-6

Kearney, D. J., Simpson, T. L., Malte, C. A., Felleman, B., Martinez, M., and Hunt, C. (2016). Mindfulness-based stress reduction in addition to usual care is associated with improvements in pain, fatigue and cognitive failures among veterans with gulf war illnes. Am. J. Med. 129, 204-214. doi: 10.1016/j.amjmed. 2015.09.015

Klimecki, O. M., Leiberg, S., Lamm, C., and Singer, T. (2013). Functional neural plasticity and associated changes in positive affect after compassion training. Cereb. Cortex 23, 1552-1561. doi: 10.1093/cercor/bhs142

Kobach, A., Nandi, C., Crombach, A., Bambonye, M., Westner, B., and Elbert, T. (2015). Violent offending promotes appetitive aggression rather than posttraumatic stress-a replication study with burundian ex-combatants. Front. Psychol. 6:1755. doi: 10.3389/fpsyg.2015.01755

Kobach, A., Schaal, S., and Elbert, T. (2014). Combat high or traumatic stress: violent offending is associated with appetitive aggression but not with symptoms of traumatic stress. Front. Psychol. 5:1518. doi: 10.3389/fpsyg.2014. 01518

Kok, B. E., and Singer, T. (2017). Effects of contemplative dyads on engagement and perceived social connectedness over 9 months of mental training: a randomized clinical trial. JAMA Psychiatry 74, 126-134. doi: 10.1001/jamapsychiatry.2016. 3360

LeGrand, C. C., Isschot, L. V., and Riaño-Alcalá, P. (2017). Land, justice, and memory: challenges for peace in Colombia. J. Latin Am. Caribbean Stud. 42, 259-276. doi: 10.1080/08263663.2017.1378381

Leiberg, S., Klimecki, O., and Singer, T. (2011). Short-term compassion training increases prosocial behavior in a newly developed prosocial game. PLoS One 6:e17798. doi: 10.1371/journal.pone.0017798

Levy, J., Goldstein, A., Influs, M., Masalha, S., Zagoory-Sharon, O., and Feldman, R. (2016). Adolescents growing up amidst intractable conflict attenuate brain response to pain of outgroup. Proc. Natl. Acad. Sci. U.S.A. 113, 13696-13701. doi: 10.1073 /pnas. 1612903113

Lieberman, M. D., Hariri, A., Jarcho, J. M., Eisenberger, N. I., and Bookheimer, S. Y. (2005). An fMRI investigation of race-related amygdala activity in AfricanAmerican and Caucasian-American individuals. Nat. Neurosci. 8, 720-722. doi: $10.1038 / \mathrm{nn} 1465$

Lindenmayer, J. P., McGurk, S. R., Khan, A., Kaushik, S., Thanju, A., Hoffman, L., et al. (2013). Improving social cognition in schizophrenia: a pilot intervention combining computerized social cognition training with cognitive remediation. Schizophr. Bull. 39, 507-517. doi: 10.1093/schbul/sbs120

Maguen, S., Lucenko, B. A., Reger, M. A., Gahm, G. A., Litz, B. T., Seal, K. H., et al. (2010). The impact of reported direct and indirect killing on mental health symptoms in Iraq war veterans. J. Trauma Stress 23, 86-90. doi: 10.1002/jts. 20434

Maguen, S., Luxton, D. D., Skopp, N. A., Gahm, G. A., Reger, M. A., Metzler, T. J., et al. (2011). Killing in combat, mental health symptoms, and suicidal ideation in Iraq war veterans. J. Anxiety Disord. 25, 563-567. doi: 10.1016/j.janxdis.2011. 01.003 
McFall, M., Fontana, A., Raskind, M., and Rosenheck, R. (1999). Analysis of violent behavior in Vietnam combat veteran psychiatric inpatients with posttraumatic stress disorder. J. Trauma Stress 12, 501-517. doi: 10.1023/A:1024771121189

Meyer-Parlapanis, D., Weierstall, R., Nandi, C., Bambonye, M., Elbert, T., and Crombach, A. (2015). Appetitive aggression in women: comparing male and female war combatants. Front. Psychol. 6:1972. doi: 10.3389/fpsyg.2015.01972

Mike, G. (2018). Durkheim's theory of violence. Int. Soc. Sci. J. 58, 41-50. doi: 10.1111/j.1468-2451.2009.01687.x

Milliken, C. S., Auchterlonie, J. L., and Hoge, C. W. (2007). Longitudinal assessment of mental health problems among active and reserve component soldiers returning from the Iraq war. JAMA 298, 2141-2148. doi: 10.1001/jama. 298.18.2141

Molenberghs, P., Gapp, J., Wang, B., Louis, W. R., and Decety, J. (2016). Increased moral sensitivity for outgroup perpetrators harming ingroup members. Cereb. Cortex 26, 225-233. doi: 10.1093/cercor/bhu195

Muchembled, A. (2010). A History of Violence. Cambridge: Polity Press.

Mullins, S. (2010). Rehabilitation of Islamist terrorists: lessons from criminology. Dynam. Asymmetric Conflict 3, 162-193.

Nandi, C., Crombach, A., Bambonye, M., Elbert, T., and Weierstall, R. (2015). Predictors of posttraumatic stress and appetitive aggression in active soldiers and former combatants. Eur. J. Psychotraumatol. 6:26553. doi: 10.3402/ejpt.v6. 26553

Odenwald, M., Hinkel, H., Schauer, E., Neuner, F., Schauer, M., Elbert, T. R., et al. (2007a). The consumption of khat and other drugs in Somali combatants: a cross-sectional study. PLoS Med. 4:e341. doi: 10.1371/journal.pmed.004 0341

Odenwald, M., Lingenfelder, B., Schauer, M., Neuner, F., Rockstroh, B., Hinkel, H., et al. (2007b). Screening for posttraumatic stress disorder among Somali excombatants: a validation study. Conflict Health 1:10. doi: 10.1186/1752-1505$1-10$

Pflueger, M. O., Franke, I., Graf, M., and Hachtel, H. (2015). Predicting general criminal recidivism in mentally disordered offenders using a random forest approach. BMC Psychiatry 15:62. doi: 10.1186/s12888-0150447-4

Poldrack, R. A., Monahan, J., Imrey, P. B., Reyna, V., Raichle, M. E., Faigman, D., et al. (2018). Predicting violent behavior: what can neuroscience add? Trends Cogn. Sci. 22, 111-123. doi: 10.1016/j.tics.2017.11.003

Raine, A. (2013). The Anatomy of Violence. The Biological Roots of Crime. New York, NY: Pantheon/Random House.

Ready, D. J., Thomas, K. R., Worley, V., Backscheider, A. G., Harvey, L. A., Baltzell, D., et al. (2008). A field test of group based exposure therapy with 102 veterans with war-related posttraumatic stress disorder. J. Trauma Stress 21, 150-157. doi: 10.1002/jts.20326

Reardon, S. (2018). Colombia: after the violence. Nature 557, 19-24. doi: 10.1038/ d41586-018-04976-7
Richeson, J. A., Baird, A. A., Gordon, H. L., Heatherton, T. F., Wyland, C. L., Trawalter, S., et al. (2003). An fMRI investigation of the impact of interracial contact on executive function. Nat. Neurosci. 6, 1323-1328. doi: 10.1038/ nn1156

Roberts, D. L., Combs, D. R., Willoughby, M., Mintz, J., Gibson, C., Rupp, B., et al. (2014). A randomized, controlled trial of Social Cognition and Interaction Training (SCIT) for outpatients with schizophrenia spectrum disorders. Br. J. Clin. Psychol. 53, 281-298. doi: 10.1111/bjc.12044

Schork, N. J. (2015). Personalized medicine: time for one-person trials. Nature 520, 609-611. doi: 10.1038/520609a

Thrasher, J., and Handfield, T. (2018). Honor and Violence: an account of feuds, duels, and honor killings. Hum. Nat. 29, 371-389. doi: 10.1007/s12110-0189324-4

Toomey, R., Kang, H. K., Karlinsky, J., Baker, D. G., Vasterling, J. J., Alpern, R., et al. (2007). Mental health of US Gulf War veterans 10 years after the war. $B r$. J. Psychiatry 190, 385-393. doi: 10.1192/bjp.bp.105.019539

Trujillo, S., Trujillo, N., Lopez, J. D., Gomez, D., Valencia, S., Rendon, J., et al. (2017). Social cognitive training improves emotional processing and reduces aggressive attitudes in ex-combatants. Front. Psychol. 8:510. doi: 10.3389/fpsyg. 2017.00510

Valk, S. L., Bernhardt, B. C., Trautwein, F. M., Bockler, A., Kanske, P., Guizard, N., et al. (2017). Structural plasticity of the social brain: differential change after socio-affective and cognitive mental training. Sci. Adv. 3:e1700489. doi: 10. 1126/sciadv. 1700489

Viding, E., McCrory, E., and Seara-Cardoso, A. (2014). Psychopathy. Curr. Biol. 24, R871-R874. doi: 10.1016/j.cub.2014.06.055

Weierstall, R., Huth, S., Knecht, J., Nandi, C., and Elbert, T. (2012). Appetitive aggression as a resilience factor against trauma disorders: appetitive aggression and PTSD in German World War II veterans. PLoS One 7:e50891. doi: 10.1371/ journal.pone.0050891

Yaganeh, Z., Dolatshahee, B., and Dogaheh, E. (2014). The effectiveness of neurofeedback training on reducing symptoms of war veterans with posttraumatic stress disorder. J. Pract. Clin. Psychol. 4, 17-24.

Conflict of Interest Statement: The authors declare that the research was conducted in the absence of any commercial or financial relationships that could be construed as a potential conflict of interest.

Copyright (c) 2019 Baez, Santamaría-García and Ibáñez. This is an open-access article distributed under the terms of the Creative Commons Attribution License (CC BY). The use, distribution or reproduction in other forums is permitted, provided the original author(s) and the copyright owner(s) are credited and that the original publication in this journal is cited, in accordance with accepted academic practice. No use, distribution or reproduction is permitted which does not comply with these terms. 